\title{
Untangling hydrological pathways and nitrate sources by chemical appraisal in a stream network of a reservoir catchment
}

\author{
M. A. Yevenes and C. M. Mannaerts \\ Department of Water Resources, Faculty of Geo-Information Science \& Earth Observation (ITC), University of Twente, \\ The Netherlands
}

Correspondence to: M. A. Yevenes (yevenesburgos@itc.nl)

Received: 29 January 2011 - Published in Hydrol. Earth Syst. Sci. Discuss.: 2 March 2011

Revised: 15 February 2012 - Accepted: 16 February 2012 - Published: 8 March 2012

\begin{abstract}
The knowledge of water source contributions to streamflow is important for understanding chemical contamination origins and the status of biogeochemical cycling in stream networks of catchments. In this study, we evaluated whether a limited number of spatially distributed geochemical tracer data sampled during different hydrological seasons were sufficient to quantify water flow pathways and nitrate sources in a catchment. Six geochemical water constituents $\left(\delta^{2} \mathrm{H}, \delta^{18} \mathrm{O}, \mathrm{Cl}^{-}, \mathrm{SO}_{4}^{2-}, \mathrm{Na}^{+}, \mathrm{NO}_{3}^{-}\right.$and $\left.\mathrm{K}^{+}\right)$of precipitation, stream water, alluvial sediment pore water and shallow groundwater of a $352 \mathrm{~km}^{2}$ agricultural catchment in the Alentejo region of Portugal were analysed. Exploratory data analysis and end-member mixing analysis (EMMA) were performed to estimate the water source mixing proportions. Residual analysis of principal components was used to identify the appropriate geochemical tracers and the number of end-members (water sources and flow paths), and their proportional contributions to streamflow were quantified. Spearman's rank correlation analysis was further used to identify nitrate origins in the streamflow. Results showed that, when using data from both wet and dry seasons, streamflow chemistry was strongly influenced by shallow groundwater. When only wet season data were modelled, streamflow chemistry was controlled and generated by three end-members: shallow groundwater, alluvial sediment pore water and precipitation. Isotope signatures of stream water were located mostly below the local meteoric water line (LMWL) and plotted along a local evaporation line (LEL), reflecting the permanence in the streamflow of shallow groundwater subjected to prior evaporation. Interpretation of isotope signatures during summer showed an isotopic enrichment in both streamflow and shallow groundwater. Measured and historical stream nitrate concentrations appeared to be strongly related to shallow groundwater. In addition, two hydrochemical data outliers for almost every solute from two sample points were identified by the analysis and could be related to local waste
\end{abstract}

water outfalls. The results of this study have improved our understanding of water source contributions to streamflow in the catchment, and also yielded indications of nitrate consumption related to biogeochemical processes in the streamflow network. Moreover, we could conclude that the relatively limited geochemical spatial sample database used in this study was an adequate input for the end-member mixing analysis and diagnostic tools to quantify water sources and nitrate origins in the streamflow of the catchment.

\section{Introduction}

Identification of flow pathways and mechanisms for streamflow generation is necessary in order to better understand the interactions between land and aquatic systems in catchments (Uhlenbrook et al., 2008). Characterizing nutrient transports in water environments is an equally important challenge because of the multiple options and pathways that a nutrient might follow in a watershed (Mulholland and Hill, 1997). Many studies have been carried out regarding the role of instream processes as decisive factors of stream water chemistry. Such processes can be strongly related to hydrological conditions such as connectivity among streams, temperature regime, rainfall occurrence and intense evaporation (Dunn et al., 2006; Y. Liu et al., 2008; Meredith et al., 2009). Recent studies have linked hydrological and geochemical aspects in order to better understand the role of water pathways in nutrient transport by streamflow (McHale et al., 2002; Bernal et al., 2006; Ocampo et al., 2006; Tesoreiro et al., 2009).

To identify streamflow components and nutrient releases at the catchment scale, water isotope approaches in conjunction with geochemical tracers have regained importance (Bernal et al., 2006; Mul et al., 2008; F. Liu et al., 2008; Meredith et al., 2009; Hrachowitz et al., 2010). Hence the use of conservative chemical tracers is again increasing rapidly 
and is nowadays considered highly suitable for conducting hydrograph separation and exploring streamflow origins and hydrological or geochemical processes occurring in the aquatic environments of watersheds (Ocampo et al., 2006; Didszun and Uhlenbrook, 2008).

An effective analytical tool to help recognize the importance of various streamflow components is the use of endmember mixing analysis (EMMA) through principal components analysis (PCA), developed by Christophersen and Hooper (1992). A water sample taken from different water origins or hydrological flow paths such as precipitation, runoff or streamflow, sediment or soil pore water, and shallow or deep groundwater represents a mixture of water that contributes to generating the streamflow. If these distinct water flow paths are considered as end-members assumed to be conservative and constant over time, it is possible to define a system of simple linear equations for calculating the mixing proportions between water flow paths. When more than two tracers are considered, EMMA can be used, with reliable results, to identify end-member values and to help to build a conceptual understanding of the streamflow generation process.

The possibility of analysing water hydrochemistry on a continuous basis and for longer time periods in larger catchments requires a very significant budget and considerable time and effort, and was beyond the scope of this research. Therefore, the aims of this study were to see whether a spatial sample-based analysis, using several seasonal observation campaigns, could be used as a data source for conducting end-member mixing analysis, using isotope and hydrochemical signatures to decipher the water and dissolved chemical (nitrate) origins in the streamflow of a catchment and the inflow in a reservoir.

\section{Data and methods}

\subsection{Site description}

The Roxo catchment is located west of the town of Beja in the province of Alentejo, South Portugal. The catchment $\left(352 \mathrm{~km}^{2}\right)$ drains into the Roxo reservoir (volume capacity $10^{8} \mathrm{~m}^{3}$ ), which has an average surface area of $11.9 \mathrm{~km}^{2}$. The stream network $\left(20 \mathrm{~km}^{2}\right)$ is composed of three intermittent streams: Chaminé-Pisoes, located in the northern section of the catchment; Juliana, located in the middle part; and Victoria, located in the southern branch of the stream network. All these small streams flow into the main reservoir of the catchment (Fig. 1). The streamflow varies strongly depending on the season. It is common to find low flow connectivity in the streams during summer periods, especially from July to September. The area is dominated by dry Mediterranean, almost semi-arid, conditions, with a mean annual temperature of $20^{\circ} \mathrm{C}$, and the long-term mean annual rainfall in the catchment area is estimated in the range of 500 to $550 \mathrm{~mm}$.
Precipitation occurs mainly between November and March. This winter period typically generates about $80 \%$ of the annual precipitation.

The Roxo reservoir was built in the early sixties and is used for supplying water to Beja city (approximately 161000 inhabitants), the local mining industry in Aljustrel and several large irrigation perimeters (ABROXO, 2009). The municipal waters from Beja city are channelled through sewers to a waste water treatment plant, and effluent is released into the Chaminé-Pisoes catchment tributary.

Hydrogeological investigations have revealed that the main productive aquifers of the upper Roxo catchment are located in the Beja-Acebuches and Beja Gabbro geotectonic complexes. These geological formations consist mainly of gabbro-dioritic rocks. The altered bedrock varies locally and can reach $30 \mathrm{~m}$ in thickness. It creates an unconfined aquifer with a shallow water table, which drains naturally into the Roxo stream network (Paralta and Oliveira, 2005). The main drainage runs from the north and north-east to the south-west and into the reservoir. The other catchment drainage originates in the south-west and drains to the north-east to finally reach the reservoir (Fig. 1).

The topography varies from nearly flat to gently sloping terrain with elevations ranging from $123 \mathrm{~m}$ at the catchment reservoir outlet to $280 \mathrm{~m}$ a.s.l. near Beja city. Soil classification, according to the FAO-UNESCO system, identified four main soil types in the catchment: Luvisols, Lithosols, Planosols and Vertisols (Sen and Gieske, 2005). Luvisols account for about $64 \%$ of the study area's soils, which makes it the dominant soil type. They are predominantly soils with $\mathrm{pH}$ around 6.0, with loam to clay loam textures, and are located in the central and southern parts. Vertisols are dominant in the northern part, overlaying the geological Gabbros of Beja formation, and have a higher $\mathrm{pH}$ and high clay content.

Land use in the Roxo catchment is dominated by agricultural activities. The main crops produced in the region are winter wheat, maize, alfalfa and sunflower as rotation crops, and olives, vineyards (grapes) and cork oak as perennial agricultural crops. Agricultural land covers more than $80 \%$ of the catchment. In addition, mining activities for zinc ( $\mathrm{Zn}$ ) and pyrite $\left(\mathrm{FeS}_{2}\right)$ from volcanogenic massive sulphide deposits are also present in the southern part of the Roxo area.

\subsection{Water sampling and analysis}

For this study, 27 sampling sites were chosen in the stream network. The sampling points were divided over three larger streams covering the north, middle and south of the catchment (Fig. 1). In total, 87 water samples (stream water, sediment pore water and shallow groundwater from wells) were collected during three periods. Sampling in wet conditions was conducted in two periods: the first during of autumn in October 2008 and the second during late winter in March and April 2009. Sampling in dry conditions took place from August to September 2009. 


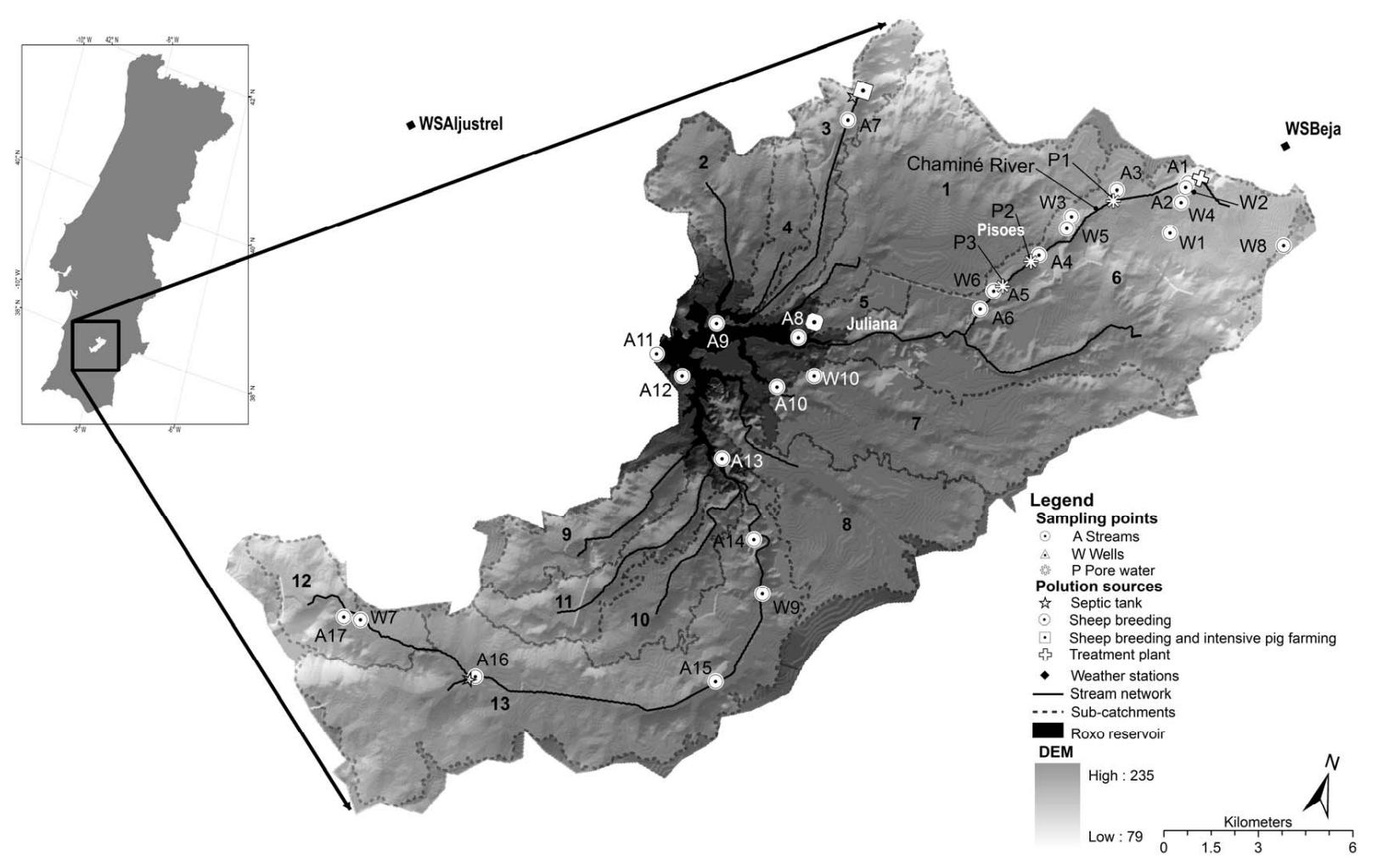

Fig. 1. Map of the study area of Roxo catchment with the principal pollution sources. Circles are the 27 sampling sites, including stream water (A), shallow groundwater (W) and pore water samples (P).

To avoid contact with the atmosphere, stream water, shallow groundwater and sediment pore water samples were taken in duplicate, using a vacuum pump technique. Pore water samples were collected by inserting a rhizon sampler syringe (Seeberg-Elverfeldt et al., 2005) into drill holes in a core $52 \mathrm{~cm}$ long located in the bottom of the stream in sites A3, A4 and A5. Samples were stored in 10-ml glass vials. Ten rhizon samplers were then inserted horizontally into the core at depths of $0,1,2,3,5,7,10$ and $20 \mathrm{~cm}$ below the sediment-water interface. For this study, we considered only four depths $(0,5,10$ and 20). To measure several physicochemical parameters $\left(\mathrm{Cl}^{-}, \mathrm{SO}_{4}^{2-}, \mathrm{Na}^{+}, \mathrm{NO}_{3}^{-}\right.$and $\left.\mathrm{K}^{+}\right)$and stable isotopes $\left(\delta^{2} \mathrm{H}\right.$ and $\left.\delta^{18} \mathrm{O}\right)$, samples were filtered in situ using Millipore $0.45 \mu \mathrm{m}$ filter pore size and a vacuum pump. After filtration, all samples were immediately stored at $4{ }^{\circ} \mathrm{C}$ in a dark environment for subsequent chemical and isotopic analyses.

Shallow groundwater samples were taken at depths ranging from 2 to $5 \mathrm{~m}$ from private and municipal wells at several locations. This water table is considered representative of the natural drainage of the groundwater aquifer towards the stream network and ultimately the Roxo reservoir.
Anion concentrations were analysed using a Hach UV-Vis spectrometer at the Faculty of Geosciences of Utrecht University. Precipitation chemistry data were extracted from the Global Atmosphere Watch (GAWSIS) ${ }^{1}$. Isotope signatures for $\delta^{2} \mathrm{H}$ and $\delta^{18} \mathrm{O}$ were determined by isotope ratio mass spectrometry in the Environmental Isotope Laboratory in Vienna, a facility certified by the International Atomic Energy Agency (IAEA). Isotope results are expressed in deviations from the Vienna Standard Mean Ocean Water (VSMOW) standard per mil, using the usual delta notation. Stable isotopes in precipitation were obtained from the IAEA and the Global Network of Isotopes in Precipitation (GNIP), using measured data for Beja city, which is located in the upper northeast of the catchment ${ }^{2}$.

\footnotetext{
${ }^{1}$ http://www.wmo.int/pages/prog/arep/gaw/gaw_home_en.html.

${ }^{2} \mathrm{http}: / / \mathrm{www}$-naweb.iaea.org/napc/ih/IHS_resources_gnip.html.
} 


\subsection{Data analysis}

\subsubsection{Hydrological data}

Daily records of rainfall data (2008-2009) were obtained from automatic weather stations located near Beja and Aljustrel. In addition, a 2008-2009 dataset of daily evapotranspiration, reservoir storage volume, historical reservoir water levels and water abstraction data was available from ABROXO (2009). An inverted reservoir water balance method was used to estimate the total catchment streamflow into the main reservoir water body. This mass balance technique consisted of estimating the reservoir inflow from the variation over time in the reservoir storage volume and the total sum of outflows from the reservoir. This method proved to give reliable estimates of catchment total streamflow and inflow in the reservoir (Vithanage, 2009). Streamflow was also measured at sampling locations in the catchment during the three sampling campaigns, using the chemical dilution technique (Hershy, 1995).

\subsubsection{Isotopic framework}

The conventional isotope hydrology concept introduced by Craig (1961) uses the relationship between $\delta^{2} \mathrm{H}$ and $\delta^{18} \mathrm{O}$ concentrations in natural waters from different places in the world and compares isotopic enrichment relative to ocean water. This relationship shows a linear correlation over the entire range of waters that have not undergone excessive evaporation and is defined by the global meteoric water line (GMWL). The GMWL was generated from isotope data of rivers, reservoirs and precipitation from various countries, and is defined by the best-fit line $\delta^{2} \mathrm{H}=8 \delta^{18} \mathrm{O}+10$. Monthly precipitation samples of any region give rise to a local meteoric water line (LMWL) and, together with the relationship to the GMWL, are useful in explaining the relationship between the water and respective hydrological processes (Karim and Veizer, 2002). The LMWL is useful for interpreting local water movements, sources, and processes to which the water has been subjected (Dansgaard, 1964).

Our isotopic framework was based on the interpretation of local evaporation lines (LEL) as described by Wolfe et al. (2007). The LEL is useful for determining the evaporation processes that have occurred in the various water sources. It is defined by a regression line through isotopic compositions of evaporating water surfaces in the catchment such as shallow groundwater. Regarding the $\delta^{*}$ symbol shown in the LEL plot (Fig. 4), it corresponds to the isotopic composition of mean weighted local precipitation and refers to water input from precipitation.

\subsubsection{End-member mixing analysis (EMMA)}

Contributions of different end-members to streamflow were determined using geochemical tracers based on EMMA in combination with diagnostic tools of mixing models. In brief, EMMA (Christophersen and Hooper, 1992) entails a mixing model for identifying potential water flow paths (endmembers) and their proportions that contribute to streamflow. EMMA embraces a principal component analysis (PCA), a commonly applied technique that is used to reduce the dimensionality of a multivariate database. The aims of PCA were (i) to find a lower dimensional space (PCA space or $U$ space) in which the stream water is found and, (ii) to describe the variability of the data. The dimensionality of the PCA space is determined by the number of principal components or eigenvectors obtained from the PCA (Eq. 1). Christophersen and Hooper (1992) proposed that the number and identification of the potential end-members could be determined by plotting the end-members in the PCA mixing space defined by stream water and defining the end-members represented in the stream water. More recently, Hooper (2003) suggested that the number (or rank) of the end-members could also be determined from stream chemistry data, using only diagnostic tools.

$\mathbf{U}=\mathbf{X}^{*} \mathbf{V}^{T}$

where $\mathbf{U}$ represents a $(n \times m)$ matrix of stream chemical data consisting of $n$ samples and $m$ one less than the number of end-members. $\mathbf{X}^{*}$ represents an $(n \times p)$ matrix, where $p$ represents the geochemical tracers. $\mathbf{V}$ has a dimension $(m \times p)$.

Diagnostic tools of mixing models can be used to determine the geochemical tracers and the number of endmembers in streams (F. Liu et al., 2008). Stream data are used to develop a correlation matrix, followed by PCA to determine eigenvectors. The standardized stream data are projected into $U$-space by multiplying the data by the eigenvectors, and then the PCA residuals are computed. If the residuals show a random pattern in a 1-D eigenvector and a high $p$ probability is found, then this means two end-members are needed (Hooper, 2003). The aim of using this combination of diagnostic tools instead of a simple mixing model is to reduce the uncertainty in choosing the number of end-members and selecting conservative geochemical tracers.

$\hat{\mathbf{X}}^{*}=\mathbf{X}^{*} \mathbf{V}_{1}^{T}\left(\mathbf{V}_{1} \mathbf{V}_{1}^{T}\right)^{-1} \mathbf{V}_{1}$

where $\hat{\mathbf{X}}^{*}$ is the standardized stream data and $\mathbf{X}^{*}$ is the projection of the standardized data using eigenvectors of $\mathbf{V}_{1}$. $\mathbf{V}_{1}$ was extracted using a correlation matrix of the stream data.

We generated four scenarios with solutes $\left(\mathrm{Cl}^{-}, \mathrm{SO}_{4}^{2-}\right.$, $\mathrm{Na}^{+}, \mathrm{NO}_{3}^{-}$and $\left.\mathrm{K}^{+}\right)$and two stable water isotopes $\left(\delta^{2} \mathrm{H}\right.$ and $\delta^{18} \mathrm{O}$ ) obtained from 87 samples of stream water, sediment pore water and shallow groundwater from wells, and additional chemistry data of precipitation in the $352 \mathrm{~km}^{2}$ catchment during 2008-2009.

1. Using the streams dataset in Matlab (R2011b version 7.13.0.564), we applied diagnostic tools such as PCA residual analysis and $p$ probability to estimate the number of end-members from stream water and the conservative tracers to be used (Hooper, 2003). Residual 
analysis was used to examine the variability of water chemistry (difference between predicted and observed tracer concentrations), which was plotted against the observed sample. A random pattern of residuals indicates a conservative mixing subspace, while a structure in the residuals can be attributed to non-conservative behaviour or poor selection of end-members (Hooper, 2003).

2. End-member mixing analysis was then used with geochemical tracers determined earlier to identify endmembers and to quantify the contributions of endmembers to streamflow. The identification of endmembers was evaluated using the distance between the original chemical compositions and $U$-space projections (PCA scores). The first $U$-space projection was used to select the end-members and examine whether the projections of end-members were different from streamflow.

3. The validation of end-member contributions (shallow groundwater, pore water and precipitation) was calculated with the distance shown as a percentage, and by dividing distance by the original chemical composition. The shorter distance the better the fit of an end-member to EMMA. This methodology is mathematically comparable to a common mixing model, for example hydrograph separation using one tracer for two components whereas we used the first $U$-space projection $\left(U_{1}\right)$ in a two-end-member solution (F. Liu et al., 2008).

\subsubsection{Spearman's rank correlation}

Once the end-member mixing analysis had been performed, we used a non-parametric Spearman's rank correlation test to investigate whether there was a relation between stream nitrate concentration $\left(\mathrm{mg} \mathrm{N}^{-1}\right)$ and the percentage contribution of end-members or water sources to the streamflow.

\section{Results}

\subsection{Streamflow and rainfall for $2008-2009$}

Streamflow in the catchment shows a strong seasonal fluctuation, with several smaller creeks of the stream network having an intermittent flow regime. Figure 2 illustrates the precipitation and streamflow response of the catchment, using a 10-day (decade) time interval. Lowest precipitation was recorded during spring and summer, typical of dry Mediterranean areas. Major rainfall events were registered during winter, particularly at the end of January 2009, reaching 54.6 and $44.3 \mathrm{~mm}$. Stream flows were generally low, around $0.05 \mathrm{~m}^{3} \mathrm{~s}^{-1}$ during summer months, mainly in August and September 2009, while the highest 10-day time-averaged value reached $1.89 \mathrm{~m}^{3} \mathrm{~s}^{-1}$ at the beginning of February 2009 .

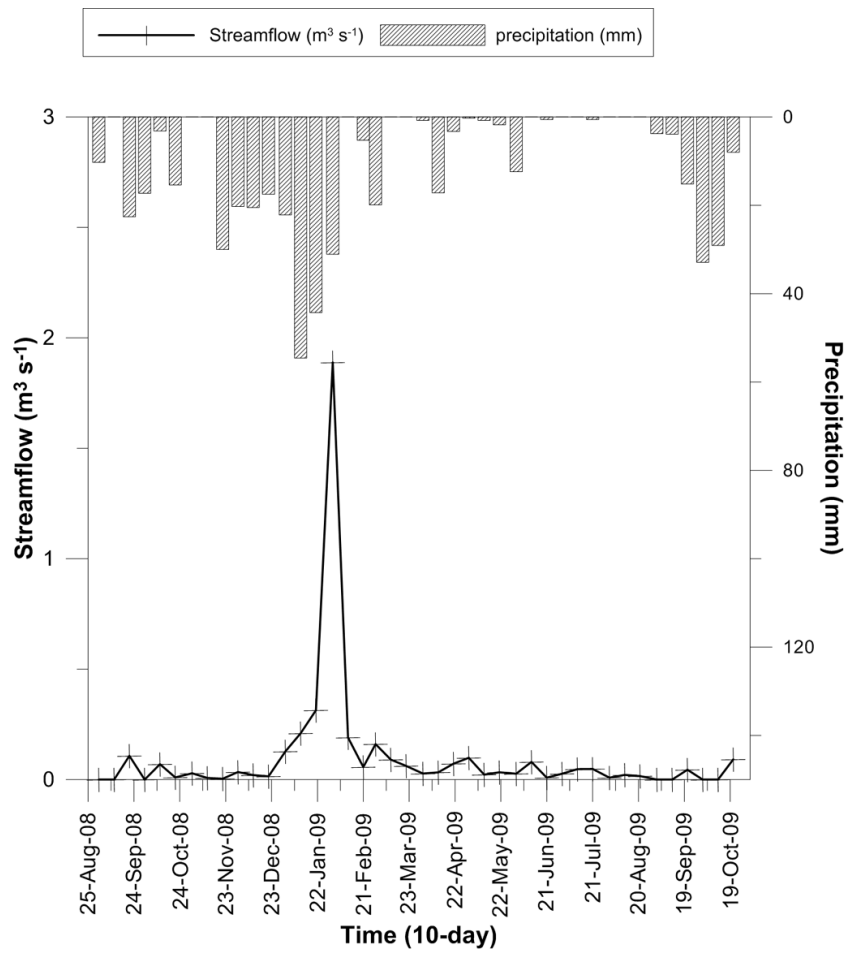

Fig. 2. Decade (10-day) time interval for precipitation and streamflow of Roxo catchment during the study period (October 2008 to September 2009).

\subsection{Spatial variation of stable water isotopes}

The stable water isotope composition (expressed as $\delta$-values) revealed systematic differences in the streams and wells, especially during September 2009 (Table 1). For the entire period (2008-2009), minimum (-24.8 and -3.92$)$ and maximum (28.5 and 8.78) composition $\left(\delta^{2} \mathrm{H}\right.$ and $\left.\delta^{18} \mathrm{O}\right)$ values were recorded in streams. Isotopic measurements of $\delta^{2} \mathrm{H}$ and $\delta^{18} \mathrm{O}$ in shallow groundwater from wells showed a mean of $-16 \%$ and $-2.58 \%$ and $-11.9 \%$ and $-1.17 \%$, respectively (VSMOW scale). Isotopic signatures of historical Beja's station precipitation data (Paralta et al., 2007) has been typically located near to the global meteoric water line (GMWL), showing a calculated LMWL of $\delta^{2} \mathrm{H}=(7.6 \pm 1.2)$ $\delta^{18} \mathrm{O}+(8.3 \pm 9.1)$ on Fig. 3. Most of the stream water sample points were located below the LMWL although some were approaching the LMWL. The LEL is shown along the regression line $\left(\delta^{2} \mathrm{H}=4.6 \delta^{18} \mathrm{O}+1.5\right)$, with a coefficient of determination $\left(R^{2}\right)$ of 0.9 (Fig. 4$)$. The LEL connects the samples from stream water, shallow groundwater and the Roxo reservoir to precipitation samples. Low water flow is shown to be enriched in the heavy isotopes in streams and shallow groundwater, and typically more depleted in the case of precipitation. 


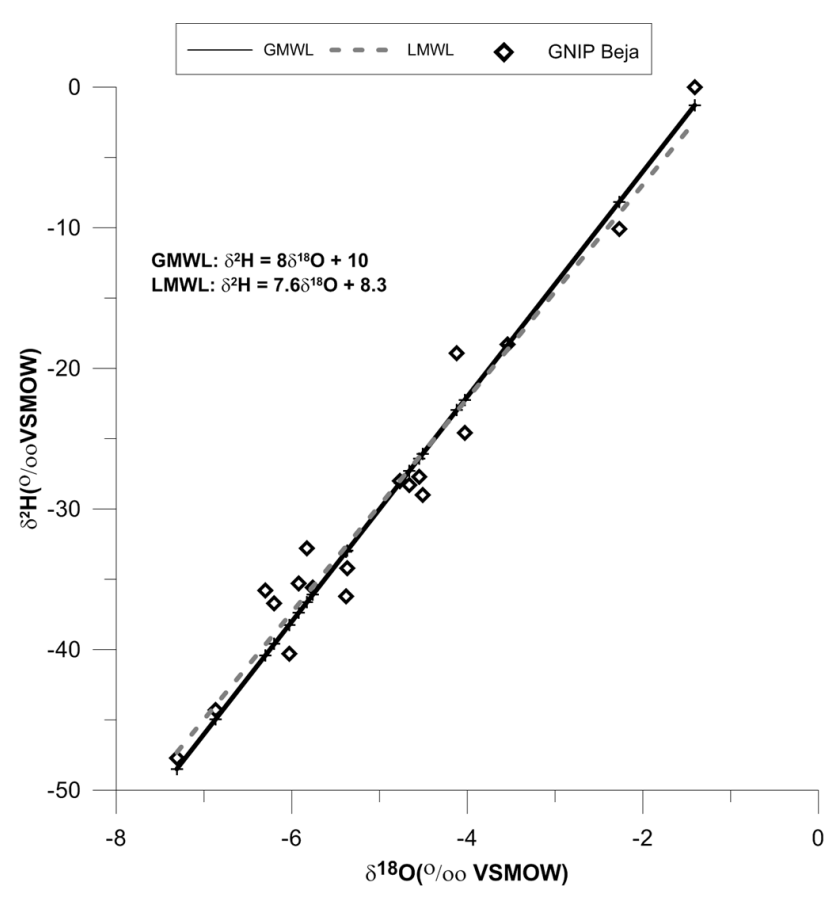

Fig. 3. Distribution of stream water isotope chemistry along the global (GMWL) and local meteoric water lines (LMWL).

\subsection{Hydrochemistry}

Figure $5 \mathrm{a}, \mathrm{b}$ and $\mathrm{c}$ indicates the field measurements for $\delta^{2} \mathrm{H}$, $\delta^{18} \mathrm{O}, \mathrm{Cl}^{-}, \mathrm{K}^{+}, \mathrm{Na}^{+}, \mathrm{NO}_{3}^{-}$and $\mathrm{SO}_{4}^{2-}$ in the streamflow, shallow groundwater and sediment pore water, respectively. Solute concentrations in streamflow did not vary significantly over the three sample periods, while spatial variation was always presented (Fig. 5a). Sites corresponding to A1, A8A17 showed important peaks in stable isotopes and solute concentrations. Higher chloride and sulphate concentrations were detected in the streamflow at site $\mathrm{A} 1$, which is close to the outfall of a municipal waste water treatment plant (Fig. 5a). Figure 5c relating to sediment pore water showed a clear trend of increasing nitrate concentration nearer to the surface water. In addition, nitrate concentration in the top of the sediment is much larger than the concentration in the surface water.

\subsection{Diagnostic tools and end-member mixing analysis}

\subsubsection{Geochemical tracers and number of end-members}

Scenario A1: We included all the data from wet and dry seasons, with five solutes as geochemical tracers $\left(\mathrm{Cl}^{-}, \mathrm{K}^{+}\right.$, $\mathrm{Na}^{+}, \mathrm{NO}_{3}^{-}$and $\mathrm{SO}_{4}^{2-}$ ) of sediment pore water, shallow groundwater and precipitation samples.

PCA residual analysis using five solutes was highly structured against measured concentrations in streamflow in the 1-D mixing space, with $R^{2}$ usually higher than 0.3 and $p=0.07$. The degree of randomness significantly increased

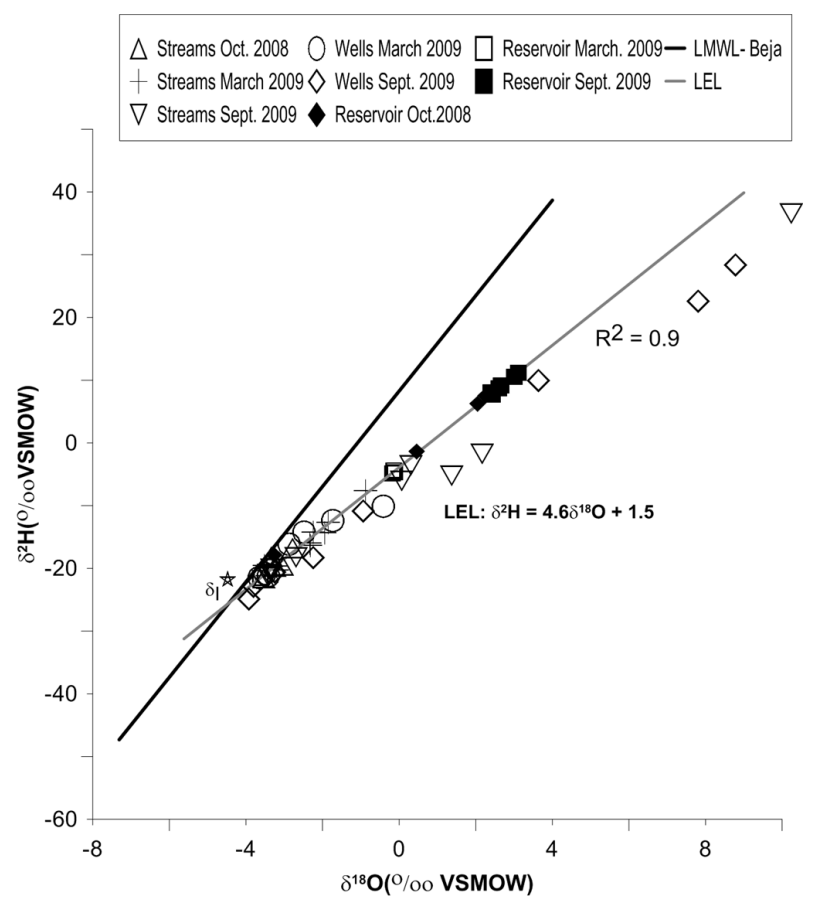

Fig. 4. Local evaporation line (LEL) of streamflow and shallow groundwater for the wet (April) and dry (September) campaigns.

in the 2-D mixing space, but only for $\mathrm{Cl}^{-}$and $\mathrm{SO}_{4}^{2-}$. The residuals in the 2-D mixing space were, however, still correlated with streamflow solute concentrations for most tracers, with $R^{2}>0.3$. Therefore, there was no random pattern between predicted and observed values, and the wellstructured residual distribution indicated that there was no conservative mixing in this scenario. Hence, using dry and wet sampling data indicated a non-conservative behaviour and also no conservative mixing of end-members. Therefore, only one single end-member is considered in the streams. Further EMMA was therefore not relevant with regard to this dataset.

Scenario A2: We included all the data from Scenario A1 and we added stable isotope data $\left(\delta^{2} \mathrm{H}\right.$ and $\left.\delta^{18} \mathrm{O}\right)$ of shallow groundwater and precipitation.

Residuals from all solutes and isotopes were also well structured against measured concentrations in streamflow in the 1-D mixing space, with $R^{2}$ usually higher than 0.4 and $p=0.08$. The residuals in the 2-D mixing space were also correlated with streamflow solute concentrations for most solutes, with $R^{2}$ near 0.6 and $p<0.01$. In conclusion, this scenario using dry and wet season data also indicated a nonconservative behaviour and no conservative mixing of endmembers. Hence, only one single end-member was found in the streams. We therefore split the datasets and removed the dry season samples from the analysis.

Scenario B1: We used only the wet season samples gathered during October 2008 and March 2009 and we used five 
Table 1. Measured values and descriptive statistics of chemical variables in the stream water, shallow groundwater and pore water samples during the studied period (October 2008, March 2009 and September 2009).

\begin{tabular}{|c|c|c|c|c|c|c|c|c|c|c|c|c|c|c|c|c|c|c|c|c|c|c|c|c|}
\hline & \multicolumn{8}{|c|}{ October 2008} & \multicolumn{8}{|c|}{ March 2009} & \multicolumn{8}{|c|}{ September 2009} \\
\hline & $\delta^{2} \mathrm{H}$ & $\delta^{18} \mathrm{O}$ & $\mathrm{Cl}^{-}$ & $\mathrm{SO}_{4}^{2-}$ & $\mathrm{Na}^{+}$ & $\mathrm{K}^{+}$ & $\mathrm{NO}_{3}$ & DO & $\delta^{2} \mathrm{H}$ & $\delta^{18} \mathrm{O}$ & $\mathrm{Cl}^{-}$ & $\mathrm{SO}_{4}^{2-}$ & $\mathrm{Na}^{+}$ & $\mathrm{K}^{+}$ & $\mathrm{NO}_{3}$ & DO & $\delta^{2} \mathrm{H}$ & $\delta^{18} \mathrm{O}$ & $\mathrm{Cl}^{-}$ & $\mathrm{SO}_{4}^{2-}$ & $\mathrm{Na}^{+}$ & $\mathrm{K}^{+}$ & $\mathrm{NO}_{3}$ & DO \\
\hline \multicolumn{25}{|l|}{ Streams } \\
\hline Max & -1.30 & 0.45 & 657 & 126 & 203 & 6.50 & 16.5 & 9.3 & -7.60 & -0.88 & 891 & 313 & 235 & 19.1 & 15.2 & 11.4 & 28.5 & 8.78 & 630 & 62.1 & 201 & 8.92 & 10 & 9.8 \\
\hline Min & -21.5 & -3.54 & 199 & 56.0 & 27.0 & 0.30 & 1.27 & 2.2 & -21.1 & -3.52 & 121 & 13.3 & 61.9 & 3.11 & 0.04 & 5.5 & -24.8 & -3.92 & 21.9 & 19.6 & 13.6 & 4.20 & 0.02 & 2.1 \\
\hline Average & -16.4 & -2.68 & 283 & 82.3 & 98.0 & 2.41 & 7.24 & 6.0 & -16.4 & -2.58 & 243 & 59.7 & 157 & 7.60 & 5.70 & 7.6 & -6.17 & 0.30 & 178 & 45.5 & 112 & 6.19 & 3.36 & 6.7 \\
\hline St. dev. & 6.82 & 1.40 & 166 & 24.2 & 56.0 & 2.70 & 5.45 & 1.7 & 4.09 & 0.85 & 217 & 85.4 & 105 & 4.64 & 5.49 & 1.74 & 20.8 & 5.10 & 187 & 13.8 & 69.0 & 1.39 & 3.57 & 1.9 \\
\hline Median & -18.1 & -3.25 & 220 & 79.0 & 82.0 & 1.20 & 4.81 & 5.7 & -16.3 & -2.33 & 197 & 40.2 & 119 & 6.27 & 5.80 & 7.4 & -18.2 & -2.25 & 120 & 49.9 & 130 & 6.18 & 2.71 & 6.9 \\
\hline $\mathrm{N}$ & 15 & 15 & 15 & 15 & 15 & 15 & 15 & 15 & 17 & 17 & 17 & 17 & 17 & 17 & 17 & 17 & 17 & 17 & 17 & 17 & 17 & 17 & 17 & 17 \\
\hline \multicolumn{25}{|l|}{ Wells } \\
\hline Max & & & 102 & 68.0 & 145.0 & 4.70 & 20.2 & 9.3 & -10.00 & -0.41 & 886 & 114 & 403 & 9.40 & 25.5 & 10 & -1.70 & 2.16 & 523 & 57.2 & 441 & 4.40 & 18.2 & 8.3 \\
\hline Min & & & 29.0 & 28.0 & 45.0 & 0.20 & 1.70 & 3.4 & -21.40 & -3.65 & 104 & 7.60 & 78.0 & 1.00 & 2.21 & 2.18 & -21.3 & -3.42 & 20.4 & 16.4 & 37.0 & 0.20 & 0.03 & 4.5 \\
\hline Average & & & 50.4 & 51.0 & 75.2 & 2.10 & 10.3 & 5.9 & -16.56 & -2.58 & 453 & 57.5 & 172 & 4.43 & 9.82 & 6.46 & -11.9 & -1.17 & 136 & 38.8 & 135 & 2.04 & 6.79 & 6.18 \\
\hline St. dev. & & & 26.9 & 15.7 & 36.0 & 1.99 & 8.18 & 2.2 & 4.64 & 1.17 & 400 & 50.8 & 106 & 2.58 & 8.58 & 2.56 & 9.2 & 2.33 & 195 & 16.0 & 134 & 1.64 & 8.40 & 1.45 \\
\hline Median & & & 39.6 & 57.9 & 65.0 & 1.35 & 9.91 & 6.1 & -16.1 & -2.87 & 159 & 30.1 & 140 & 4.60 & 7.11 & 6.35 & -12 & -1.32 & 52.9 & 39.2 & 77.0 & 2.30 & 2.49 & 6.1 \\
\hline $\mathrm{N}$ & & & 10 & 10 & 10 & 10 & 10 & 10 & 10 & 10 & 10 & 10 & 10 & 10 & 10 & 10 & 10 & 10 & 10 & 10 & 10 & 10 & 10 & 10 \\
\hline \multicolumn{25}{|c|}{ Pore water } \\
\hline Max & & & 177 & 17.0 & 263 & 4.07 & 5.43 & & & & 197 & 58.3 & 172 & 5.02 & 1.55 & & & & 326 & 82 & 246 & 8.9 & 2.48 & \\
\hline Min & & & 63.0 & 7.90 & 124 & 3.17 & 1.96 & & & & 173 & 39.7 & 77.0 & 1.20 & 0.13 & & & & 21.0 & 4.7 & 4.5 & 4.2 & 0.28 & \\
\hline Average & & & 115 & 11.5 & 165 & 3.83 & 3.76 & & & & 187 & 52.0 & 111 & 3.81 & 0.87 & & & & 191.9 & 69.4 & 121.6 & 6.5 & 0.85 & \\
\hline St. dev. & & & 40.4 & 3.39 & 49.2 & 0.34 & 1.27 & & & & 9.10 & 5.35 & 34.0 & 1.36 & 0.50 & & & & 105.0 & 72.1 & 90.2 & 1.6 & 0.70 & \\
\hline Median & & & 114 & 10.6 & 150 & 3.97 & 4.02 & & & & 186 & 52.8 & 97.0 & 4.30 & 0.80 & & & & 232.5 & 44.8 & 160.0 & 6.8 & 0.55 & \\
\hline $\mathrm{N}$ & & & 20 & 20 & 20 & 20 & 20 & & & & 20 & 20 & 20 & 20 & 20 & & & & 20 & 20 & 20 & 20 & 20 & \\
\hline
\end{tabular}

solutes as geochemical tracers $\left(\mathrm{Cl}^{-}, \mathrm{K}^{+}, \mathrm{Na}^{+}, \mathrm{NO}_{3}^{-}\right.$and $\mathrm{SO}_{4}^{2-}$ ) of streamflow.

Figure 6a shows the distributions of residuals of $\mathrm{Cl}^{-}, \mathrm{Na}^{+}$ and $\mathrm{SO}_{4}^{2-}$ in a random pattern in the 1-D mixing space, with $R^{2}$ values less than 0.2 and $p=0.4$. In contrast, $\mathrm{NO}_{3}^{-}$showed a highly structured pattern, with $R^{2}$ of 0.90 and $p<0.001$, and $\mathrm{K}^{+}$with $R^{2}$ of 0.42 and $p=0.03$ and which was not enough for it to be taken into account in the next analysis. The variability increased in the 2-D mixing space, with $R^{2}$ less than 0.1 and $p>0.2$. Therefore, according to this variability in the first and secondary components, the streamflow chemistry was controlled by the three solutes $\mathrm{Cl}^{-}, \mathrm{Na}^{+}$and $\mathrm{SO}_{4}^{2-}$ and defined by conservative 2-D mixing space, which means three end-members and can give us signals of flowpath proportional contributions.

Therefore, a new PCA was made using only $\mathrm{Cl}^{-}, \mathrm{Na}^{+}$and $\mathrm{SO}_{4}^{2-}$, which are conservative upon mixing, and these solutes were employed in EMMA using the three end-members (sediment pore water, shallow groundwater and precipitation). PCA scores as $U$-space projections were calculated using the eigenvectors extracted from these conservative tracers.

Scenario B2: We used the data from Scenario A1 and available stable isotopes $\left(\delta^{2} \mathrm{H}\right.$ and $\left.\delta^{18} \mathrm{O}\right)$ of streamflow. Figure $6 \mathrm{~b}$ shows the distributions of residuals between original concentrations, and predicted values for the 1-D and 2$\mathrm{D}$ mixing spaces referred to the main two principal components. This figure shows that the distributions of residuals of $\mathrm{Cl}^{-}, \mathrm{SO}_{4}^{2-}, \delta^{2} \mathrm{H}$ and $\delta^{18} \mathrm{O}$ show a near-random pattern in the 1-D mixing space, with $R^{2}$ values less than 0.2 and $p>0.3$. The variability increased in the 2-D mixing space for the four tracers, with $R^{2}$ less than 0.1 and $p>0.4$. In contrast, in this scenario $\mathrm{Na}^{+}, \mathrm{NO}_{3}^{-}$and $\mathrm{K}^{+}$presented more structured values for $R^{2}$ of $0.25,0.96$ and 0.54 and $p<0.1$, respectively, which was not enough to take them into account in the next analysis. Therefore, according to this variability the streamflow chemistry was primarily controlled by conservative 2-D mixing space, and then three endmembers can give us signals of flowpath proportional contributions. The geochemical tracers $\left(\mathrm{Cl}^{-}, \mathrm{SO}_{4}^{2-}, \delta^{2} \mathrm{H}\right.$ and $\delta^{18} \mathrm{O}$ ) detected with the residual analysis were used to run a new PCA for the studied period, EMMA and streamflow separation. Two eigenvectors were adequate (indicating three potential end-members) for shallow groundwater, pore water and precipitation.

A closer look at the residual plots from Scenarios B1 and B2 (Fig. 6a and b) permitted two outliers to be detected (originating in the two field campaigns from sample point $\mathrm{A} 1$ and A9). Confrontation with field observations and evidence indicated point source contamination from a waste water treatment plant outfall (A1) releasing residual waste water directly into the stream network (Fig. 1). This waste outfall typically increases salt concentrations as $\mathrm{Cl}^{-}$and $\mathrm{SO}_{4}^{2-}$ as well as nitrogen levels i.e. ammonia and organic-N, but not nitrate concentrations as shown in Fig. 6a and b. The PCA and residual analysis therefore proved to be good diagnostic tools for the detection of contamination as well. The practical use of outliers in diagnostic analysis and EMMA was also suggested by Hooper (2003).

\subsubsection{Identification and validation of end-members}

A new PCA was made for Scenarios B1 and B2, considering the three potential end-members and with only the geochemical tracers that had passed the residual analysis: $\mathrm{Cl}^{-}, \mathrm{SO}_{4}^{2-}$ and $\mathrm{Na}^{+}$for Scenario $\mathrm{B} 1$ and $\delta^{2} \mathrm{H}, \delta^{18} \mathrm{O}, \mathrm{Cl}^{-}, \mathrm{SO}_{4}^{2-}$ for $\mathrm{B} 2$. PCA scores as $U$-space projections were calculated using the eigenvectors extracted from these geochemical tracers using 
(a)
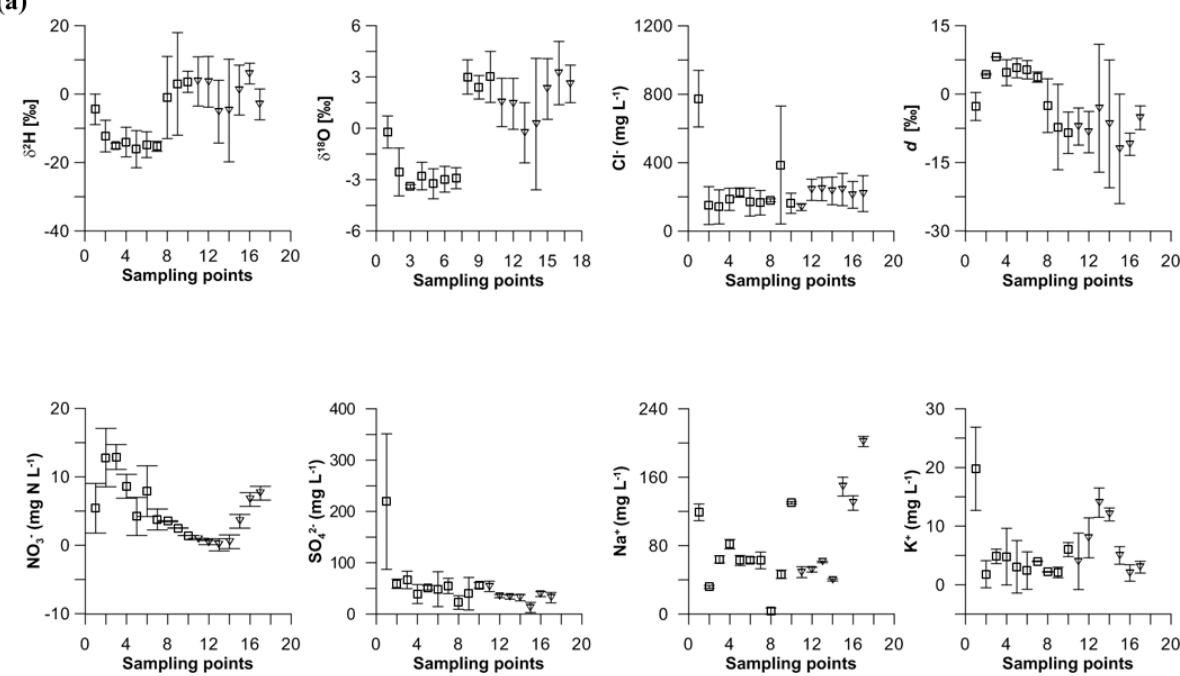

(b)
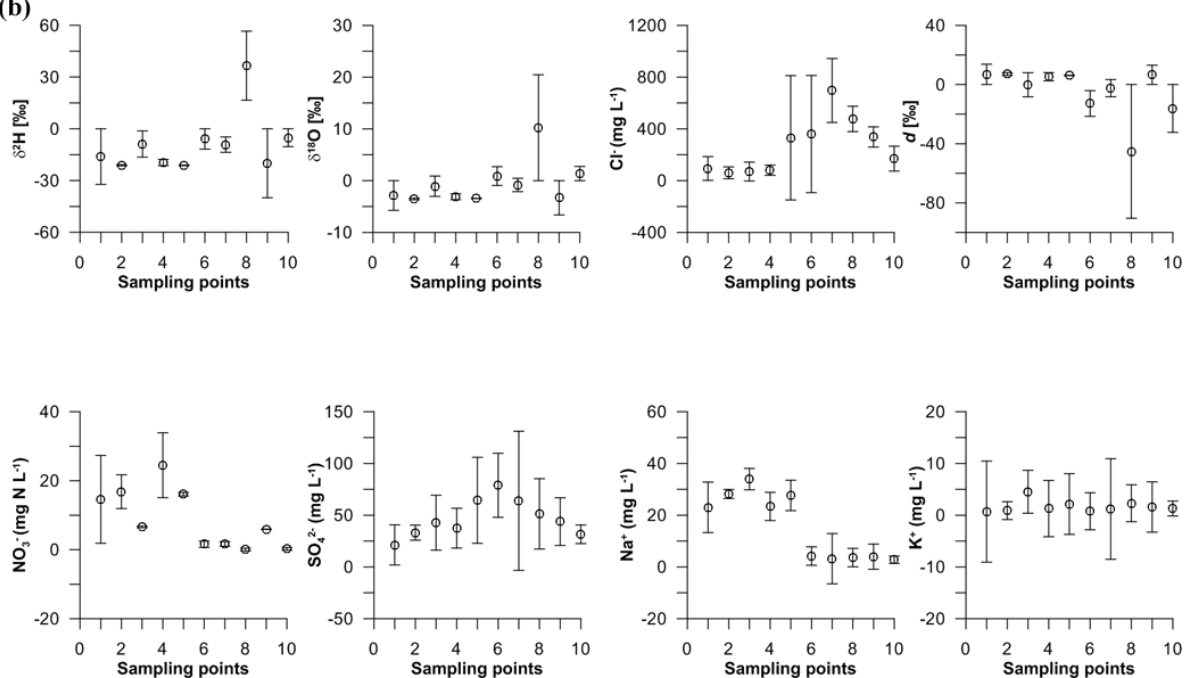

(c)
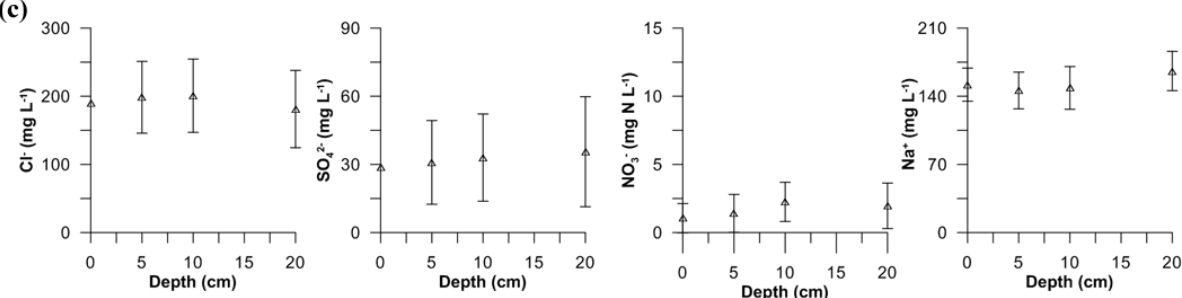

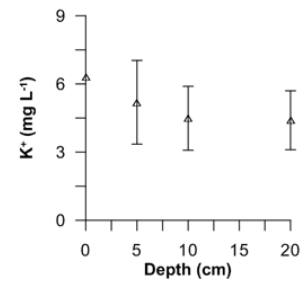

Fig. 5. Chemical composition of $\delta^{2} \mathrm{H}, \delta^{18} \mathrm{O}, \mathrm{Cl}^{-}, \mathrm{SO}_{4}^{2-}, \mathrm{Na}^{+}, \mathrm{NO}_{3}^{-}$and $\mathrm{K}^{+}$in: (a) surface water (squares indicate the Chaminé river to the reservoir, inverted triangles indicate the reservoir to Victoria river), (b) shallow groundwater and (c) pore water during the three periods. Sampling points (A1 to A17) are numbered from 1 to 17 in the plots. 

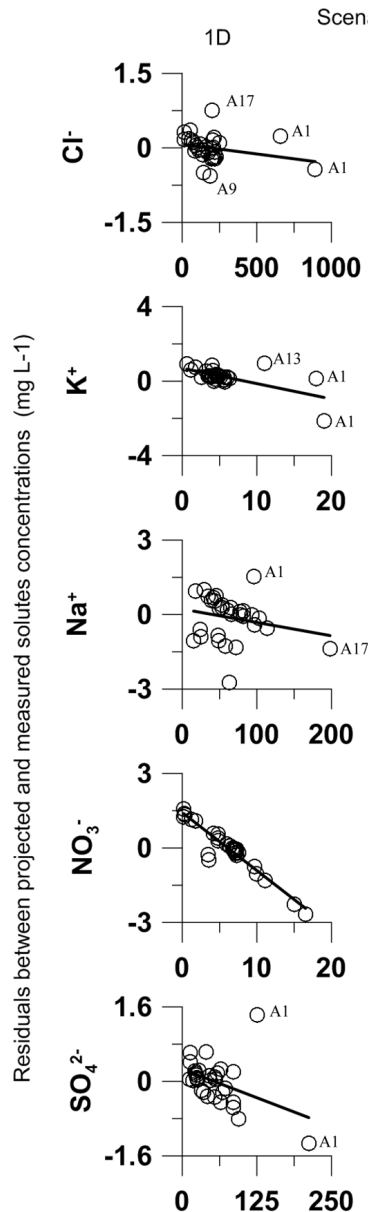

Measured solutes concentrations (mg L-1)

Fig. 6a. Plot of residuals versus original concentrations of solutes and stable isotopes for wet and dry seasons from the 1-D mixing space and 2-D mixing spaces for Scenario B1 (outliers are identified in the plots).

the correlation matrix indicated in Sect. 2.3.3. The difference between the first $\left(U_{1}\right)$ and secondary $\left(U_{2}\right) U$-space was projected for the appraisal of end-members. $U_{1}$ and $U_{2}$ values of shallow groundwater samples were slightly higher than those of streamflow and similar to those of pore water.

Finally, end-members were identified using the orthogonal distance between their original compositions and $U$-space projections from the PCA. For Scenario B1, a hydrograph separation permitted the proportional contributions from the end-members to be derived: groundwater $52 \%$, sediment pore water $38 \%$ and precipitation $10 \%$. For Scenario B2, this data scenario analysis led to the following proportional contributions from the end-members: groundwater $56 \%$, sediment pore water $32 \%$ and precipitation $12 \%$ - which is similar to Scenario B1.
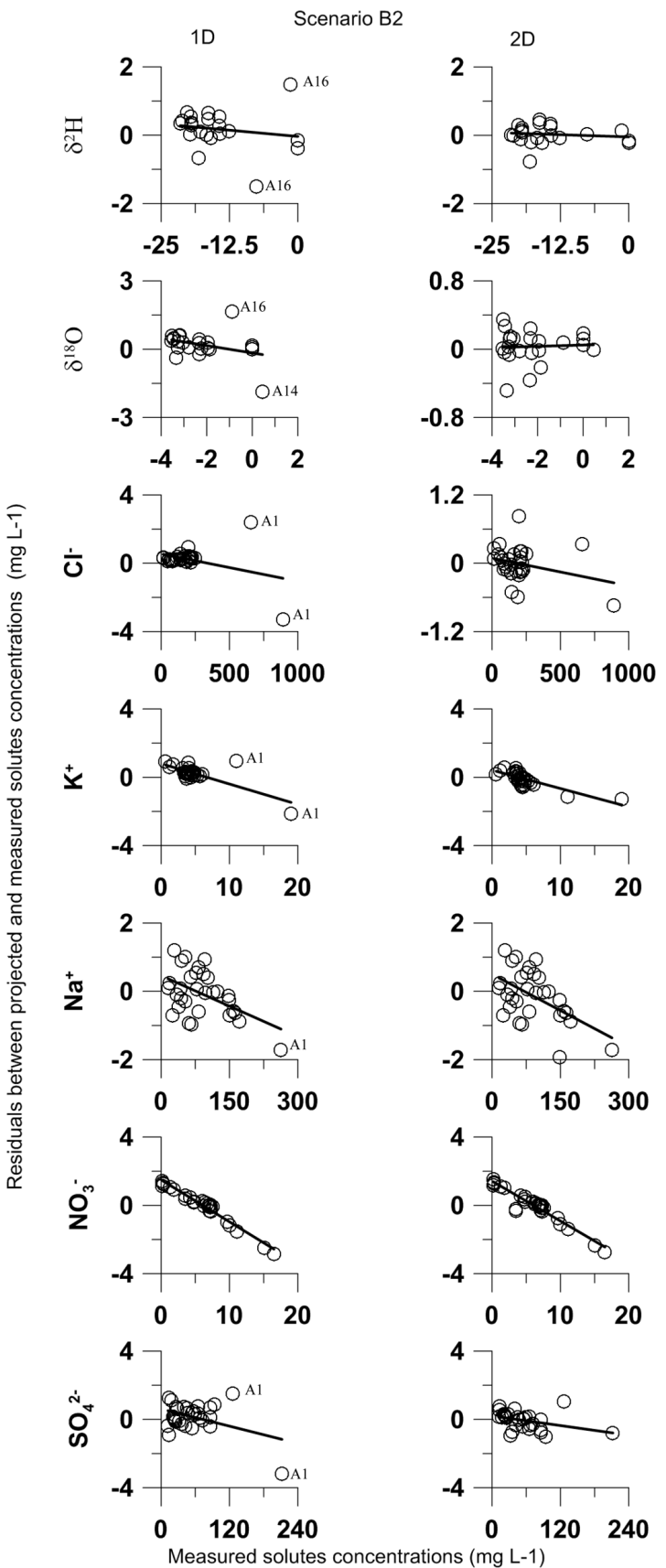

Fig. 6b. Plot of residuals versus original concentrations of solutes and stable isotopes for wet and dry seasons from the 1-D mixing space and 2-D mixing spaces for Scenario B2 (outliers are identified in the plots).

\subsection{Sources of nitrate}

Once we had obtained the estimated water source contributions through EMMA, we then correlated the end-member contributions with the stream nitrate concentrations for the wet season. Here we used a Spearman's rank correlation test to assess relations between stream nitrate concentration 
and the percentage of streamflow for the main end-members. Shallow groundwater and sediment pore water percentages showed a good correlation with stream nitrate values ( $\rho_{\text {wells }}$ and $\rho_{\text {porewater }} 0.56$ and 0.79 , respectively). Apparently pore water is playing an important role in the exchange of nitrate with the stream water. An additional Spearman's rank correlation test using historical nitrate data of June 2003 and December 2004 from shallow groundwater and stream water yielded similar results ( $\rho_{\text {wells }}: 0.52$ and 0.65$)$ and confirmed our hypothesis on nitrate source origins (Table 2). Moreover, if we compared our highest $\mathrm{Cl}^{-}$concentrations in stream water and shallow groundwater, the concentrations of chloride showed synchronicity between concentrations of streamflow and shallow groundwater. This implies that chloride concentrations in the stream depend upon the relative contribution from shallow groundwater, where $\mathrm{Cl}^{-}$concentrations are more stable than in the stream waters.

\section{Discussion}

\subsection{Water isotopes and solutes abundance in Roxo catchment}

Over the entire study period, a low streamflow regime prevailed and isotope signatures were below the LMWL and close to, but slightly different from, the LEL, reflecting a mixture of shallow groundwater and a small influence of rainfall sources (Figs. 3 and 4). The precipitation values define the LMWL, which is only marginally above the GMWL (see Fig. 3). The slight deviation of the LMWL from the GMWL is a confirmatory point, since such behaviour of precipitation composition has been commonly observed in similar drier regions (Meredith et al., 2009). The data from the LEL (Fig. 4) provided information on the secondary processes acting on the water as it travels from its source into the surface water. However, the LEL for stream water and shallow groundwater, $\delta^{2} \mathrm{H}=4.6 \delta^{18} \mathrm{O}+1.5$ (Fig. 4), indicated that these waters have experienced evaporation. These enriched or higher $\delta$-values for $\delta^{2} \mathrm{H}$ and $\delta^{18} \mathrm{O}$ isotopes can be observed during September 2009 (Table 1). Stream waters (8.78\%o) were enriched in heavy isotopes as a consequence of evaporation with respect to shallow groundwater (from $-3.42 \%$ o to $2.16 \%$ ). It is known that during low-flow periods in semiarid areas evaporation generates characteristically heavy isotope enrichment in residual surface waters above $+3 \%$ (Gonfiantini, 1986). The difference in stable isotope composition between the shallow groundwater and the stream water can be used for tracing the contributions of water to the streams. This is hinted in Fig. 4, where shallow groundwater samples are not that close to the stream samples in summer sampling in the LEL. This fractional contribution is confirmed by the EMMA in the next sections.

Heavier isotopic values were also related to higher anion concentrations. Chloride and sulphate, as suitable indicators of the concentration of salt in the water due to their conservative nature showed high concentrations (Table 1). In general, $\mathrm{Cl}^{-}$concentrations were largest in the streams, ranging from 21.9 to $891 \mathrm{mg} \mathrm{l}^{-1}$ and from 13.3 to $313 \mathrm{mg} \mathrm{l}^{-1}$, respectively. These values are due mainly to the shallow depth and intermittent pools in several sections in the stream network that permit water stagnation and evaporation. Major values were observed in the first sampling point (A1; corresponding to the stream location downstream of the waste water treatment plant outfall) (Figs. 1 and 5a). It is known that $\mathrm{NaCl}$ contributions from households can thoroughly change water quality (Appelo and Postma, 2007). High chloride and sulphate concentrations in wells showed high correlation $(r=0.97)$, indicating an evaporative mechanism in combination with a longer residence time. Outliers corresponding to site A1 were identified using the residual plots from Scenarios B1 and B2 (Fig. 6a and b). This indicated either errors in the data or different processes controlling the chemistry of the water samples.

\subsection{Evaluation of end-member mixing analysis}

The numbers of end-members and conservative geochemical tracers were determined by combining chemical and isotope data from stream water, based on Christopher and Hooper (1992) and Hooper (2003). The selection of endmembers and number of conservative tracers was quantitatively evaluated using diagnostic tools of mixing models as residual analysis from PCA (Fig. 6a and b). Two scenarios for the wet season campaign with different combinations of solutes and isotopes were well reproduced (Fig. 6a and b).

We agree that the seasonal campaigns using approximately 30 points for hydrochemistry and isotopes and additional information on continuous streamflow can be criticized for using a small sample size in time. However, this data analysis permitted us to verify to what extent relatively limited spatial samples and a few discrete but well-chosen sample periods could indicate source contributions of water and nitrate to a catchment stream network.

\subsection{Biogeochemical control}

Hydrological flow paths have significant functions in controlling catchment-scale biogeochemical processes. Contributions of water flow paths identified using geochemical tracers can be used to distinguish hydrological and biogeochemical control of nitrogen (Mulholland and Hill, 1997). Therefore, nitrate levels in streamflow can be predicted using several flow components determined by geochemical tracers, and then compared with measured values. Over- and under-estimation of nitrate concentrations in stream water suggest gain or loss of nitrate during streamflow generation, and thus identify the dominant processes controlling this nutrient (Mulholland, 2004). In our study, shallow groundwater is the main contributor to the streamflow and shows a positive 
Table 2. Historical levels ( $\mathrm{mg} \mathrm{N}^{-1}$ ) and the Spearman's Rho coefficient $(\rho)$ between measured nitrate concentrations in shallow groundwater and the proportion of water from the space projection of EMMA.

\begin{tabular}{|c|c|c|c|c|c|}
\hline Date & $\begin{array}{l}\text { Water } \\
\text { sample }\end{array}$ & $\begin{array}{l}\mathrm{NO}_{3}^{-} \\
\text {range }\end{array}$ & $\begin{array}{l}\text { Spearman } \\
\operatorname{rank}(\rho)\end{array}$ & $\mathrm{N}$ & Reference \\
\hline \multirow{2}{*}{ June 2003} & streams & $0.78-16.6$ & - & 25 & \multirow{2}{*}{$\begin{array}{l}\text { Historical campaign from Water Resource } \\
\text { Department* }\end{array}$} \\
\hline & wells & $3.5-17.7$ & 0.52 & 25 & \\
\hline \multirow{2}{*}{ December 2004} & streams & $0.29-12$ & - & 2 & \multirow{2}{*}{ Paralta et al. (2007) } \\
\hline & wells & $0.61-14.2$ & 0.65 & 11 & \\
\hline \multirow{2}{*}{ May 2006} & streams & - & - & & \multirow{2}{*}{ Paralta et al. (2007) } \\
\hline & wells & $7.9-33$ & - & 11 & \\
\hline October 2008 & wells & $1.7-20.2$ & 0.49 & 10 & \multirow{2}{*}{ Our study } \\
\hline March 2009 & wells & $2.2-25.6$ & 0.56 & 10 & \\
\hline
\end{tabular}

* Faculty of Geo-information Science and Earth Observation, University of Twente.

relation with stream nitrate concentrations. However, indirect evidence of the importance of in-stream processes also comes from the analysis, showing that nitrate concentrations in the streams are lower than in the shallow groundwater. This difference cannot be explained by a simple mixing of water coming from the small tributaries to the main stream. It can be most probably attributed to nitrate consumption such as denitrification in the stream water or streambed. This can be demonstrated for instance by lower $\left(<5 \mathrm{mg} \mathrm{l}^{-1}\right)$ dissolved oxygen concentrations (DO) in the streams (Table 1). However, it would be necessary to quantify the in-stream assimilation, nitrification or denitrification processes in the stream water and sediment.

Preliminary experimental analysis and the results of this study in sediment pore water also suggest that in-stream processes are occurring in the streambed. Pore water values show that nitrate concentrations decreased below the interface stream water-sediment and later slightly increased with depth, which is likely involving biogeochemical reactions (Fig. 5c). As well, conservative solutes such as $\mathrm{Cl}^{-}$varied only slightly with depth in the sediment. One explanation of the low nitrate concentration at the water-sediment interface is the nitrate consumption and the microbial activity at the interface and in the top layer of the sediment (Curie et al., 2009). The limited length $(20 \mathrm{~cm})$ of the sediment core permitted us to identify the biogeochemical interactions at the sediment water interface, but not the full pathway towards the groundwater (Pfenning and McMahon, 1996).

The higher nutrient concentrations in some points of the streams appear to come from the localized organic-rich materials and sediments transported by superficial slope runoff and deposited naturally near the stream network. In addition, the presence of livestock, such as herds of cattle, sheep breeding or goats and intensive pig farming (Fig. 1) that use the stream network as a source of drinking water, may induce additional fertilization and local differences in stream chemistry.

\section{Conclusions}

This study of the intermittent stream network of the upper Roxo catchment in South Portugal involved three seasonal spatial sampling campaigns and quantitative hydrochemical and isotope analysis. Our objective was to see whether a spatial sample-based analysis, using seasonal observation campaigns, could be used as a data source for conducting endmember mixing analysis to identify water and nitrate sources to the streamflow. The non-parametric Spearman's rank analysis was used to correlate source contributions to nitrate levels in the streamflow. End-member mixing analysis in combination with exploratory analysis was used to identify and quantify the proportional contributions of the main water sources to the streamflow. The analysis used geochemical tracer data from precipitation, stream water, alluvial sediment pore water and shallow groundwater.

The use of a relatively limited number ( $\sim 30$ points) of spatially distributed sampling points in one dry and two wet seasons permitted us to distinguish shallow groundwater as the major contributor to streamflow in all analysis periods. Proportional contributions in the two scenarios were around $50 \%$ for groundwater, followed by sediment pore water $(\sim 40 \%)$ and rainfall $(\sim 10 \%)$. The largest hydrological source contributor, shallow groundwater, appears also directly related to stream nitrate concentrations. A high pore water proportion in the streamflow means that it contributes significantly to the control of the water chemistry of the streams. A relation between stream nitrate and precipitation and also direct surface runoff could not be derived from the 
datasets. The analysis suggests that the main nitrate pathway to the stream network in this catchment is through soil leaching and re-appearance in the shallow aquifer baseflow. This biogeochemical aspect, together with the other nitrogen cycle components in the catchment, is currently being investigated and will be reported in another research contribution. Further studies would also be necessary in order to elucidate stream nitrate responses to extreme storm events.

Acknowledgements. This study was supported by the Faculty of Geo-Information Science and Earth Observation (ITC) of the University of Twente, which financed fieldwork campaigns through a $\mathrm{PhD}$ research grant. We gratefully acknowledge the help and data support of Jorge Maia of COTR, Rui Nobre of Escola Agraria de Beja, and Carlos Marques of the ABROXO Irrigation Authority. We thank Rafael Bermudez for logistic and technical support in the 2008-2009 fieldwork campaigns and the ITC MSc student Chenai Madabombe from Zimbabwe for her contribution to the data collection and preliminary analysis work. The authors would like to thank David Rossiter and the anonymous reviewers for their valuable comments and suggestions to improve the manuscript.

Edited by: A. D. Reeves

\section{References}

ABROXO: Meteorological data of Roxo reservoir station, Assoc. Water Users of Roxo, Technical bulletin, 2009 (in Portuguese).

Appelo, C. A. J. and Postma, D.: Geochemistry, Groundwater and Pollution, 2nd Edn., A.A. Balkema Publishers, Leiden, The Netherlands, 649 pp., 2007.

Bernal, S., Butturini, A., and Sabater, F.: Inferring nitrate sources through end-member mixing analysis in an intermittent Mediterranean stream, Biogeochemistry, 81, 269-289, 2006.

Christophersen, N. and Hooper, R. P.: Multivariate analysis of stream water chemical data: the use of principal components analysis for the end-member mixing problem, Water Resour. Res., 28, 99-107, 1992.

Craig, H.: Isotopic variations in meteoric waters, Science, 133, 1702-1703, 1961.

Curie, F., Ducharne, A., Sebilo, A., and Bendjoudi, M.: Denitrification in a hyporheic riparian zone controlled by river regulation in the Seine river basin (France), Hydrol. Process., 23, 655-664, 2009.

Dansgaard, W.: Stable isotopes in precipitation, Tellus (Sweden), 16, 436-468, 1964.

Didszun, J. and Uhlenbrook, S.: Scaling of dominant runoff generation processes: Nested catchments approach using multiple tracers, Water Resour. Res., 44, W02410, doi:10.1029/2006WR005242, 2008.

Dunn, S. M., Vinogradoff, S. I., Thornton, G. J. P., Bacon, J. R., Graham, M. C., and Farmer, J. G.: Quantifying hydrological budgets and pathways in a small upland catchment using a combined modeling and tracer approach, Hydrol. Process., 20, 3049-3068, 2006.

Gonfiantini, R.: Environmental isotopes in lake studies, in: Handbook of Environmental Isotope Geochemistry, Vol. 2, Elsevier, Amsterdam, 13 pp., 1986.
Herschy, R. W.: Streamflow Measurement, E. \& F. N. Spon, 2nd Edn., London, UK, 524 pp., 1995.

Hooper, R. P.: Diagnostic tools for mixing models of stream water chemistry, Water Resour. Res., 39, 1055, doi:10.1029/2002WR001528, 2003.

Hrachowitz, M., Bohte, R., Mul, M. L., Bogaard, T. A., Savenije, H. H. G., and Uhlenbrook, S.: On the value of combined event runoff and tracer analysis to improve understanding of catchment functioning in a data-scarce semi-arid area, Hydrol. Earth Syst Sci., 15, 2007-2024, doi:10.5194/hess-15-2007-2011, 2011.

Karim, A. and Veizer, J.: Water balance of the Indus river basin and moisture source in the Karakoram and Western Himalayas: implications from hydrogen and oxygen isotopes in river water, J. Geophys. Res.-Atmos., 107, 4362, doi:10.1029/2000JD000253, 2002.

Liu, F., Bales, R. C., Conklin, M. H., and Conrad, M. E.: Streamflow generation from snowmelt in semi-arid, seasonally snowcovered, forested catchments, Valles Caldera, New Mexico, Water Resour. Res., 44, W12443, doi:10.1029/2007WR006728, 2008.

Liu, Y., Fan, N., An, S., Bai, X., Liu, F., Xu, Z., Wang, Z., and Liu, S.: Characteristics of water isotopes and hydrograph separation during the wet season in the Heishui River, China, J. Hydrol., 353, 314-321, 2008.

McHale, M. R., McDonnell, J. J., Mitchell, M. J., and Cirmo, C. P.: A field-based study of soil water and groundwater nitrate release in an Adirondack forested watershed, Water Resour. Res., 38 , 1031, doi:10.1029/2000WR000102, 2002.

Meredith, K. T., Hollins, S. E., Hughes, C. E., Cendon, D. I., Hankin, S., and Stone, D. J.: Temporal variation in stable isotopes $\left({ }^{18} \mathrm{O}\right.$ and $\left.{ }^{2} \mathrm{H}\right)$ and major ion concentrations within the Darling river between Bourke and Wilcania due to variable flows, saline groundwater influx and evaporation, J. Hydrol., 378, 313-324, 2009.

Mul, M., Mutiibwa, R. K., Uhlenbrook, S., and Savenije, H.: Hydrograph separation using hydrochemical tracers in the Makanya catchment, Tanzania, Phys. Chem. Earth, 33, 151-156, 2008.

Mulholland, P. J.: The importance of in-stream uptake for regulating stream concentrations and outputs of $\mathrm{N}$ and $\mathrm{P}$ from a forested watershed: evidence from long-term chemistry records for Walker Branch Watershed, Biogeochemistry, 70, 403-426, 2004.

Mulholland, P. J. and Hill, W. R.: Seasonal patterns in streamwater nutrient and dissolved organic carbon concentrations: separating catchment flow path and in-stream effects, Water Resourc. Res., 33, 1297-1306, 1997.

Ocampo, C., Oldham, C. E., Sivapalan, M., and Turner, J.: Hydrological versus biogeochemical controls on catchment nitrate export: a test of the flushing mechanism, Hydrol. Process., 20, 4269-4286, 2006.

Paralta, E. A. and Oliveira, M. M.: Assessing and modelling hard rock aquifer recharge based on complementary methodologies: a case study in the Gabbros of Beja aquifer system (South Portugal), 2nd Workshop of the Iberian Regional Working Group on Hardrock Hydrogeology, Évora, Portugal, 15 pp., 2005.

Paralta, E. A., Carreira, P., and Ribeiro, L. F.: Assessing agriculture pollution in the Beja aquifer using nitrogen isotopes (South Portugal), International Symposium on Advances in Isotope Hydrology and its Role in Sustainable Water Resources Management, IHS-2007, IAEA, Vienna, Austria, 6 pp., 2007. 
Pfenning, K. S. and McMahon, P. B.: Effect of nitrate, organic carbon, and temperature on potential denitrification rates in nitraterich riverbed sediments, J. Hydrol., 187, 283-295. 1996.

Seeberg-Elverfeldt, J., Schlüter, M., Feseker, T., and Kölling, M.: Rhizon sampling of porewaters near the sediment-water interface of aquatic systems, Limnol. Oceanogr.-Meth., 3, 361-371, 2005.

Sen, P. and Gieske, A.: Use of GIS and remote sensing in identifying recharge zones in an arid catchment: a case study of Roxo river basin, Portugal, J. Nepal Geol. Soc., 31, 25-32, 2005.

Tesoreiro, A., Duff, J. H., Wolock, D., and Spahr, N.: Identifying pathways and processes affecting nitrate and orthophosphate inputs to streams in agricultural watersheds, J. Environ. Qual. Technical Reports, Surface Water Quality, 38, 1892-1900, 2009.
Uhlenbrook, S., Didszun, J., and Wenninger, J.: Source areas and mixing of runoff components at the hillslope scale: a multitechnical approach, Hydrol. Sci. J., 53, 741-753, 2008.

Vithanage, I.: Analysis of nutrient dynamics in Roxo catchment using remote sensing data and numerical modelling, MSc Thesis, ITC, Enschede, 103 pp., 2009.

Wolfe, B. B., Karst-Riddoch, T. L., Hall, R. I., Edwards, T., English, M. C., Palmini, R., McGowan, S., Leavitt, P. R., and Vardy, S. R.: Classification of hydrological regimes of northern floodplain basins (Peace-Athabasca Delta, Canada) from analysis of stable isotopes $\left({ }^{18} \mathrm{O}\right.$ and $\left.{ }^{2} \mathrm{H}\right)$ and water chemistry, Hydrol. Process., 21, 151-168, 2007. 